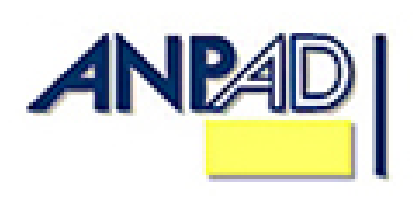

Disponível em

http://www.anpad.org.br/rac

RAC, Curitiba, v. 14, n. 4, art. 2,

pp. 594-614, Jul./Ago. 2010

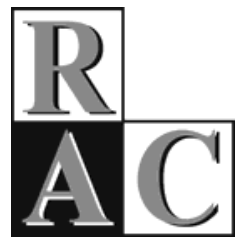

\title{
As Quatro Faces de RH: Analisando a Performance da Gestão de Recursos Humanos em Empresas no Brasil
}

\section{The Four Faces of HR: Analyzing the Performance of Human Resource Management in Brazilian Companies}

\begin{abstract}
Betania Tanure *
Doutora em Administração pela Brunel University, Reino Unido. Professora Titular da PUC Minas, Brasil e professora convidada do Insead, França e da London Business School, Inglaterra.

Paul Evans Doutor em Gestão e Psicologia Organizacional pelo Massachusetts Institute of Technology, Estados Unidos. Professor no INSEAD/França.

Vera L. Cançado Doutora em Administração pela UFMG. Professora Titular na Faculdade Pedro Leopoldo, Pedro Leopoldo/MG, Brasil.
\end{abstract}

\footnotetext{
* Endereço: Betania Tanure

PUC Minas/Fundação Dom Cabral, Alameda do Ingá, 840, Conj. 301, Vale do Sereno, Nova Lima/MG, 34000000. E-mails: betaniatanure@fdc.org.br / betaniatanure@betaniatanure.com
}

Copyright (C) 2010 RAC. Todos os direitos, inclusive de tradução, são reservados. É permitido citar parte de artigos sem autorização prévia desde que seja identificada a fonte. 


\section{RESUMO}

Este artigo tem como objetivo analisar o desempenho do RH em empresas brasileiras, a partir do modelo das Quatro Faces da GRH, proposto por Tanure, Evans e Pucik (2007): o executor, o construtor, o parceiro de mudança e o navegador. Para tal, foram utilizados dados secundários de uma survey com 172 presidentes das 500 maiores empresas no Brasil; e se analisaram os resultados de um estudo de caso, realizado em uma empresa financeira - Brasilprev. Os dados do estudo de caso foram coletados por meio de 14 entrevistas individuais, de três grupos focais com 15 colaboradores de diversos níveis hierárquicos, e de 68 questionários. Os resultados da survey com os presidentes indicaram que o RH é considerado predominantemente executor em empresas de capital nacional; para as de capital multinacional, predomina o RH construtor e o parceiro de mudança. Os resultados do estudo de caso indicam que, na percepção dos colaboradores da Brasilprev, o RH está caminhando para a face de parceiro de mudança. Entretanto as práticas de RH adotadas pela empresa, apesar de serem de última geração e modernas, não estão articuladas entre si e não apresentam consistência interna e externa. Podese concluir que, para empresas brasileiras, o RH executor ainda prevalece, apesar da utilização de modernas práticas de gestão de recursos humanos.

Palavras-chave: gestão de pessoas; gestão de recursos humanos; gestão estratégica de pessoas; as quatro faces de RH.

\section{ABSTRACT}

This paper aims to analyze Brazilian companies' Human Resource Management [HRM] performance. We used the Four Faces of the HRM model developed by Tanure, Evans and Pucik (2007) as a framework. The four faces are: executor, constructor, change partner and navigator. To achieve our goal, we discussed the result of a survey with 172 presidents of the 500 biggest companies in Brazil. We also analyzed a case study of a finance company - Brasilprev. The data was collected during 14 interviews, from three focal groups with 15 collaborators from all the hierarchical levels and 68 questionnaires. The results of the presidents' survey showed that the HRM is mainly considered as an executor in Brazilian capital companies. The constructor and the change partner faces prevail in multinational capital companies. According to the case study results, the HRM of Brasilprev is moving to the change partner face. Nevertheless, even if a company's HR practices are modern and sophisticated, they do not present internal or external consistency. Therefore, we can conclude that the executor face still prevails in Brazilian companies, although modern HRM practices are utilized.

Key words: human resource management [HRM]; people management; strategic human resource management; the four faces of HRM. 


\section{INTRODUÇÃO}

Existe grande controvérsia sobre a contribuição da gestão de recursos humanos [GRH] para o desempenho das empresas, bem como se questiona se suas práticas deveriam ser universais ou relativistas (Evans, Pucik, \& Barsoux, 2002). Tanure (2005), ao analisar as abordagens convergente e divergente, defende uma terceira corrente, denominada divergência convergente, mais adequada para fazer frente aos paradoxos que as empresas vêm enfrentando, a partir da intensificação da globalização. Práticas como as de gestão de pessoas devem adequar-se às especificidades regionais e de cada empresa, enquanto outras práticas ligadas a dimensões da organização, como a estratégia, podem ser universais.

Nesse contexto, para atender às demandas das organizações globais, o RH precisa assumir funções cada vez mais complexas, até mesmo paradoxais. Diversos autores, como Burke e Cooper (2005), Ulrich (1997) e Weiss (1999), desenvolveram modelos que auxiliam na compreensão da atuação performance do RH. Entre os vários modelos, destaca-se a contribuição de Evans et al. (2002) que, a partir de pesquisas na Europa e nos Estados Unidos, concluem que a relação entre a GRH e a performance organizacional pode ser explorada à luz de três diferentes faces ou etapas:

a) A do construtor, que edifica os fundamentos das funções de RH de maneira consistente;

b) A do parceiro de mudança, que busca o realinhamento da organização às estratégias e ao ambiente externo;

c) A do navegador, que auxilia a organização em face das contradições e paradoxos inerentes ao mundo globalizado.

Essas faces correspondem às necessidades das grandes empresas internacionalizadas. Entretanto estudos de Tanure et al. (2007) e pesquisas realizadas no Brasil (Fischer \& Albuquerque, 2001; Hanashiro, Texeira, \& Zebinato, 2001; Sarsur, 1997, dentre outros) indicam a necessidade de considerar uma face anterior à do construtor, denominada executor. Em muitas empresas brasileiras, o RH restringe-se aos processos de registro e movimentação de pessoas, cumprindo uma função burocrática cartorial. Essas estratégias são facilmente identificáveis em pequenas e médias empresas, mas também estão presentes nas empresas de grande porte. Nestas, as práticas e políticas de RH podem ser sofisticadas; mas não se observa uma coerência com a estratégia da organização. Esse aspecto é central para o entendimento da inclusão da face do executor no modelo (Tanure et al., 2007).

Tal realidade não se restringe às empresas brasileiras. Elvira e Davilla (2005), analisando a atuação de RH na América Latina, demonstram haver também idiossincrasias e abordagens regionais também nas empresas dos nos diversos países pesquisados, semelhantes às encontradas no Brasil. Coexistem, no mesmo espaço, corporações multinacionais, conglomerados familiares e pequenas empresas, bem como grande parcela de empresas no setor informal, o que apresentam corresponde a uma diversidade nas práticas de $\mathrm{RH}$.

Não se pretende afirmar que esse modelo se restrinja somente à realidade de empresas brasileiras ou de países em desenvolvimento. O que se defende neste artigo é que a inclusão dessa quarta face, denominada de executor, anterior à face do construtor, emergiu a partir da análise de dados e da realidade brasileira. O desenvolvimento histórico e econômico do Brasil determinou algumas características culturais que ainda permeiam a racionalidade da gestão organizacional e implicam peculiaridades que se traduzem em uma forma local de gerenciar recursos humanos, sendo, pois, importante considerá-los ao se pensar um modelo para analisar a GRH no Brasil.

A partir de tais considerações, levanta-se a questão central deste artigo: De que forma a GRH vem atuando em empresas brasileiras? Buscou-se analisar a performance do RH em empresas brasileiras, a partir do modelo das Quatro Faces da GRH, proposto por Tanure et al. (2007). Para tal, foram utilizados dados secundários de uma survey com 172 presidentes das 500 maiores empresas no Brasil 
(Tanure, 2006) e se analisaram os resultados de um estudo de caso realizado em uma empresa financeira - Brasilprev. Os dados do estudo de caso foram coletados por meio de entrevistas individuais, de grupos focais e de questionários. O estudo de caso serviu para aprofundar como a GRH atua no Brasil, possibilitando a generalização teórica, enquanto os resultados da survey permitiram a generalização dos dados para a realidade de empresas brasileiras.

\section{REFERENCIAL TEÓRICO}

Uma das discussões sobre a Gestão de Recursos Humanos [GRH] nas últimas décadas tem girado em torno da polaridade da universalidade ou relatividade de suas práticas, conforme apontado por diversos autores, como Evans e Farquhar (1989), Glanz e Bailey (1993), Godard e Delaney (2000) e Whitfield e Poole (1997), entre outros. Deveriam as práticas e políticas de RH ser similares? Ou deveriam adequar-se às características de cada país, ao tamanho e ao negócio de cada organização? Entre as abordagens universalista e relativista, principalmente após o sucesso das práticas japonesas nos anos 80, autores como Huselid (1995), Lawler (1992), Neal e Tromley (1995) e Pfeffer (1998) argumentam que, apesar de não existir uma única e melhor prática para a gestão de pessoas, alguns aspectos seriam comuns, principalmente os que incentivam a gestão participativa - os chamados sistemas e equipes de alto desempenho.

A partir da análise dessas duas abordagens, convergente e divergente, e dos estudos realizados por Child (2002), Tanure (2005) propõe uma terceira abordagem denominada divergência convergente, mais adequada à gestão dos paradoxos inerentes às empresas globalizadas. Segundo a autora, as diferenças entre países e regiões, refletidas nas organizações, são mais evidentes em relação a valores. Apesar da necessidade de valores comuns entre as subsidiárias ou unidades de uma organização - os chamados valores corporativos - as práticas de gestão de pessoas têm de se adaptar à realidade local, às características únicas e peculiares de cada empresa. Já outras dimensões, como estratégia ou estrutura organizacional, não sofreriam impactos significativos do ambiente cultural no qual a empresa está localizada. Essa abordagem parece ser mais integradora. Independentemente de onde a empresa se localize, alguns desafios são comuns a todas, como a aplicação de princípios de boa governança corporativa, a redução de custos, o desenho das estruturas organizacionais e algumas outras questões que visam a garantir condições básicas de competitividade. Porém a estrutura ou prática implantada é traduzida e interpretada diferentemente em culturas diversas.

A argumentação adotada por este artigo funda-se na abordagem da divergência convergente, ao defender a inclusão de uma quarta face na proposição apresentada por Evans et al. (2002) para a GRH. Em termos da convergência, observa-se a adoção das clássicas funções de RH pelas empresas, independentemente de outras variáveis intervenientes. Em termos de divergência na adoção de práticas, a análise do desenvolvimento histórico e econômico dos países desenvolvidos e as respectivas práticas e políticas de $\mathrm{RH}$ em comparação com a dos países em desenvolvimento, em especial o Brasil, demonstram que diferenças acentuadas têm implicações para a GRH.

Há uma variedade desconcertante de práticas de GRH nas empresas e nos diversos países. A controvérsia sobre a contribuição da gestão de recursos humanos [GRH] para o desempenho da empresa está presente nas discussões entre executivos e acadêmicos (Arthur \& Boyles, 2007; Becker \& Gerhart, 1996; Becker \& Huselid, 2006; Cappelli \& Newmark, 2001; Lepak, Takeuchi, Erhardt, \& Colakoglu, 2006). Uma razão para a controvérsia e a confusão criadas em torno da questão é não observar que a contribuição que a GRH pode oferecer ao desempenho organizacional pode apresentar aspectos distintos, caracterizados como quatro faces, as quais devem ser entendidas como etapas, mesmo que no cotidiano não sejam necessariamente sequenciais. Esse modelo, originalmente desenvolvido por Evans et al. (2002), a partir da análise da gestão de pessoas na Europa e nos Estados Unidos, apresentava três faces para o RH - o construtor, o parceiro de mudança e o navegador. A inclusão da face do executor para a realidade brasileira é resultado de pesquisas e experiências de três décadas com empresas multinacionais e brasileiras de estudos desenvolvidos por Tanure et al. (2007), 
que concluíram pela necessidade de adequação das práticas de gestão à cultura local. Não se pretende aqui afirmar que essa face seja exclusiva da realidade brasileira, mas apenas que, da análise das especificidades da realidade do desenvolvimento de empresas brasileiras e de dados sobre a performance do RH no Brasil, emergiu essa face do executor.

O desenvolvimento de RH no país, além de quase meio século de atraso em relação ao dos países desenvolvidos, atrelou-se à entrada das multinacionais, principalmente à indústria automobilística, na década de 1960, e à importação das práticas gerenciais dos grandes centros, conforme discutido em Cançado, Coutinho, Sant'Anna e Almeida (2005), Fischer e Albuquerque (2001), Lacombe (2006), Sarsur (1997) e Wood (1995).

Uma análise em um nível mais superficial poderia demonstrar que as práticas de RH no Brasil são semelhantes às desenvolvidas nos países centrais. Entretanto, por detrás de uma fachada de modernidade, observa-se incoerência entre o discurso, que utiliza a retórica gerencialista norteamericana, e a realidade, que remete à ambiguidade e práticas peculiares, e à não aderência do $\mathrm{RH}$ aos negócios das organizações (Bosquetti \& Albuquerque, 2005; Lacombe, 2006; Vasconcelos, Mascarenhas, \& Vasconcelos, 2006). A partir da abertura do mercado, na década de 1990, diversas empresas brasileiras buscaram desenvolver técnicas e práticas de gestão de recursos humanos cada vez mais modernas. Muitas dessas empresas tornaram benchmarking no mercado, como atestam as premiações das revistas de negócios e diversos estudos realizados no Brasil (Fischer \& Albuquerque, 2001; Sarsur, 1997; Wood, 1995, dentre outros). Entretanto, em muitas empresas brasileiras, essas práticas demonstram descolamento ou divergência entre o discurso e prática, podendo-se questionar o grau efetivo de contribuição do RH para o negócio das empresas (Bosquetti \& Albuquerque, 2005; Castro, Kilimnik \& Sant'Anna, 2008; Lacombe, 2006; Tanure et al., 2007; Vasconcelos et al., 2006).

Essa incoerência pode ser atribuída, em parte, à tendência de importação e implantação de técnicas gerenciais estrangeiras, resultante do modelo de colonização do país, da miscigenação étnica e do próprio desenvolvimento social do povo brasileiro, que se traduziu em plasticidade e permeabilidade às influências externas, segundo Caldas e Wood (1999). Esses traços da cultura brasileira ajudam a entender a distância entre o real e o faz-de-conta ou o para inglês ver, expressão usada no país para explicar o que é apenas aparência, um dos aspectos importantes na história e na cultura do país.

Essas dimensões históricas e culturais têm fortes impactos fortes na gestão de pessoas. De todos os campos da administração, a gestão de pessoas (ainda que haja diferenças em relação aos seus diversos aspectos) é geralmente considerada como a mais sensível ao contexto local. A programação cultural é uma razão fundamental disso. Diante do exposto, pode parecer que, para responder a tal especificidade, o melhor caminho seria transferir a gestão de pessoas inteiramente para as subsidiárias locais, adotando-se a perspectiva divergente/relativista. O ajuste das práticas da GRH ao contexto local é explicado como escolha; na verdade, a gestão de pessoas não é domínio monolítico.

Algumas práticas da área são mais amarradas a questões culturais do que outras, o que reforça a argumentação deste artigo, favorável à abordagem da divergência convergente e à necessidade da inclusão da face do executor ao modelo das Quatro Faces da GRH.

A face do executor, conforme Tanure et al. (2007), refere-se ao exercício das clássicas funções operacionais de recursos humanos: recrutamento e seleção, treinamento e desenvolvimento, avaliação de desempenho, cargos e salários, relações trabalhistas. A perspectiva do executor é centrada no fazer, na ação, sendo as funções, entretanto, as funções desalinhadas entre si e descoladas da estratégia da empresa. $\mathrm{O}$ foco é no processo, em detrimento dos resultados.

Os resultados das pesquisas realizadas por Tanure et al. (2007) em empresas brasileiras, respaldados por diversas outras pesquisas, como as de Bosquetti e Albuquerque (2005), Castro et al. (2008), Dutra (2002), Fischer e Albuquerque (2001), Lacombe (2006), Sarsur (1997) e Wood (1995), indicam a existência de dois grandes segmentos nessa face do executor: o primeiro é típico das pequenas empresas, responsável pelas tarefas legais e burocráticas da área, representado pelo Departamento de Pessoal [DP]. Entretanto não é raro encontrar esse tipo de atuação também em empresas de médio e 
grande porte. No segundo segmento, observam-se empresas que utilizam ferramentas de gestão de última geração, mas desalinhadas entre si e/ou sem aderência às estratégias da empresa. O discurso sobre a importância dos recursos humanos, apesar de articulado pelo presidente, pelos diretores e profissionais da área, não encontra respaldo no dia-a-dia da gestão. Normalmente, essas ferramentas são importadas dos grandes centros, dando ares de modernidade a área de RH, conforme Tanure et al. (2007). A modernidade dessas ferramentas tende a encobrir a inconsistência e a falta de articulação entre a GRH e a estratégia do negócio, tendência observada por Caldas e Wood (1999) em relação à importação de modelos de gestão estrangeiros em empresas brasileiras.

Portanto o executor concentra-se no fazer por si só, sem atentar para a consistência interna ou externa dos processos de RH. A perspectiva teórica que sustenta essa face é frágil, pois as práticas e ferramentas, apesar de serem de última geração, estão desarticuladas entre si e desalinhadas da estratégia da organização. Tais situações indicam que a execução deveria estar vinculada à estratégia do negócio, com a construção de fundamentos sólidos e consistentes entre si, característicos da segunda face da GRH.

A construção é a segunda face ou etapa. Nela, os fundamentos da GRH são ajustados para garantir sua coerência interna, a fim de que a estratégia da empresa seja apoiada por uma correta política e prática de GRH. A perspectiva teórica que sustenta a face do construtor é a do ajuste interno, centrado na coerência interna dos elementos da GRH e de outros componentes do sistema de trabalho. A construção é a etapa em que se edifica a infra-estrutura, sendo uma perspectiva orientada para o interior da própria empresa, conforme apontam Tanure et al.(2007).

Essa é a face mais familiar para os profissionais de $\mathrm{RH}$ e para a maioria dos textos sobre administração de pessoal, nos quais a GRH está organizada em torno de arcabouços próprios para essas atividades básicas, conforme apontado por Chiavenato (1997), Dessler (2002), Jackson e Schuler (1999), Milkovich e Boudreau (1997), Noe, Hollenbeck, Wright e Gerhart (1999), Torrington e Hall (1995) e outros. As organizações necessitam das várias tarefas básicas e vitais relativas aos recursos humanos, como as de atrair, motivar e manter pessoas. Essa visão tradicional da GRH, baseada nas atividades, pode confundir-se com a face do executor, se não se considerar a questão mais importante da face de construção: o todo é mais importante que a soma das partes, ou seja, a forma como essas diversas atividades se alinham entre si e com os objetivos organizacionais e individuais, construindo uma consistência interna da função. Subjacente à idéia de consistência está o conceito de adequação. Segundo Evans et al. (2002), a adequação das práticas aos objetivos organizacionais significa que elas têm de ser talhadas para circunstâncias específicas.

A elaboração de fundamentos consistentes e sólidos pode levar anos, até décadas. Forças poderosas que favorecem a consistência aparecem com o tempo, podendo resultar em forte resistência à mudança. Como consequência, alguns profissionais de RH tendem a ficar presos à face de construção dos fundamentos de $\mathrm{RH}$, tornando-se administradores dos seus próprios sistemas, em vez de antecipar as mudanças de mercado, de tecnologia e de estratégia. O construtor corre o risco de se transformar num zelador, algumas vezes no sentido pejorativo de zelador administrativo. Manter a adequação ou a consistência interna torna-se um fim em si mesmo, à custa do comprometimento, da competência ou do desempenho estratégico. Quando a função de zelador se instala fortemente, a primeira face da GRH - a execução - passa a predominar sobre a segunda face (Tanure et al, 2007).

Diferentemente, o enfoque da terceira face são as mudanças necessárias para atingir novos objetivos estratégicos e, ao mesmo tempo, implementar estratégias que facilitem essas mudanças. Na terceira face, o realinhamento, a GRH deve atuar de forma compatível com as mudanças do ambiente externo, o que é geralmente chamado de gestão estratégica dos recursos humanos por muitos autores como Lengnick-Hall e Lengnick-Hall (1988), Meshoulam e Baird (1987) e Wright e MacMahon (1992). O foco da ação de RH deve ser na parceria com os gerentes de linha para obter a reconfiguração e a mudança, de maneira a implementar efetivamente cada nova estratégia. A perspectiva teórica que sustenta a função de parceiro de mudanças é a de ajuste externo entre uma organização e seu ambiente competitivo, isto é, a adequação preconizada pela teoria da contingência. 
Quando muda o ambiente ou a estratégia, o processo de realinhamento de pessoas envolve o descongelamento da configuração organizacional. Esse processo de realinhamento é mais do que a tarefa técnica de implementação de mudanças por meio da modificação de práticas de RH, isoladas da estratégia e do negócio. Não se trata de abordagem voltada para as mudanças externas, na qual novos objetivos estratégicos são rapidamente posicionados, em forma de modismos. Quando a adequação externa tem foco maior, em detrimento da adequação interna, gera-se uma imagem de inconsistência nas práticas de GRH. Tais aspectos são amplamente observados em pesquisas de vários autores, como Caldas e Wood (1999), Castro et al. (2008), Fischer e Albuquerque (2001), Hanashiro et al. (2001), Sarsur (1997), Tanure et al. (2007) sobre a atuação da GRH no Brasil. Essa tendência à implementação de mudanças pode ser, em parte, explicada pela grande plasticidade e aderência às práticas importadas (Caldas \& Wood, 1999).

Nessa face, existe ainda o risco da fixação em mudanças, o que pode advir de processos mal estruturados, com objetivos de longo prazo pouco claros e/ou em função de descontinuidades. Tanure et al. (2007) chamam a atenção para o risco do ziguezague da mudança - muda-se por mudar fenômeno que gera investimentos, sem a contrapartida de benefícios. Esse ciclo pode repetir-se e criar desconfiança em torno de programas e iniciativas de mudanças entre os empregados, que podem aprender a ignorar a retórica da mudança.

Equilibrar a atenção às questões do presente, enquanto se investe na construção do futuro, significa navegar entre paradoxos e dualidades, uma das principais funções da GRH na face seguinte. A quarta face pode ser chamada de direção. Aqui, fatores estratégicos e os de RH estão, de fato, profundamente interligados. O foco está no desenvolvimento das capacidades da organização e nas pessoas, para prosperarem em mundo de contínua mudança; é administrar construtivamente as tensões entre forças opostas. Esse quarto papel desempenhado pelo RH é entendido como o de um navegador que transita entre forças contraditórias, aqui denominadas de dualidades (ou paradoxos).

Entre os muitos paradoxos, Tanure et al. (2007) destacam alguns que vêm fazendo parte da realidade organizacional e dos desafios de $\mathrm{RH}$, que precisa precisam capacitar os gestores para transitar entre forças opostas: curto prazo x longo prazo; operacional x estratégico; cooperação x competição; descentralização x centralização; processos x estrutura x pessoas, entre outros. É importante frisar que tais dualidades não são excludentes, mas demandam uma busca de equilíbrio dinâmico. O pendulum passa de um lado para outro, em contexto também mutável e, dessa forma, a grande máxima passa a ser a de ter de construir o futuro no presente, conforme apontam Evans et al. (2002). Esses desafios fazem parte da atribuição do papel do RH navegador. O navegador não pode resolver ou eliminar as tensões entre opostos. No entanto é possível criar um contexto organizacional, de maneira que essas tensões funcionem como forças propulsoras do desenvolvimento e não como fontes de conflito. A direção é particularmente relevante para os desafios da empresa transnacional.

Qualquer que seja a forma da organização, ela terá de trabalhar com ambiguidades, incertezas, informações equivocadas e mutantes. O foco da quarta face da GRH está na criação de um ambiente organizacional capaz de utilizar a tensão entre os opostos, como propulsão do sucesso e do desenvolvimento das competências organizacionais e das pessoas, para produzir resultados em ambiente de mudança contínua. Dessas quatro faces, a menos explorada na literatura é a do navegador.

Para concluir, a Tabela 1 apresenta a caracterização das Quatro Faces da GRH, focando as atividades desenvolvidas por cada face; a perspectiva teórica e a metáfora passam a indicar a função. 
Tabela 1

As Quatro Faces da Gestão de Recursos Humanos

\begin{tabular}{|c|c|c|c|c|}
\hline & Atividade & $\begin{array}{l}\text { Foco de } \\
\text { Atenção }\end{array}$ & $\begin{array}{l}\text { Perspectiva } \\
\text { Teórica }\end{array}$ & Função \\
\hline Execução & $\begin{array}{l}\text { Atividades desconectadas da } \\
\text { estratégia, mesmo usando-se } \\
\text { ferramentas sofisticadas }\end{array}$ & Ação & Fazer & EXECUTOR \\
\hline Construção & $\begin{array}{l}\text { Fundamentos - acertando os } \\
\text { elementos básicos }\end{array}$ & $\begin{array}{l}\text { Consistência } \\
\text { interna }\end{array}$ & $\begin{array}{l}\text { Ajuste interno } \\
\text { Adequação }\end{array}$ & CONSTRUTOR \\
\hline Realinhamento & $\begin{array}{l}\text { Adaptação às mudanças do } \\
\text { ambiente; implementação de } \\
\text { estratégias; reconfiguração }\end{array}$ & Mudanças & Ajuste externo & $\begin{array}{l}\text { PARCEIRO DE } \\
\text { MUDANÇAS }\end{array}$ \\
\hline Direção & $\begin{array}{l}\text { Capacidade de gerenciar } \\
\text { contextos paradoxais }\end{array}$ & $\begin{array}{l}\text { Tensão construtiva } \\
\text { entre opostos }\end{array}$ & $\begin{array}{l}\text { Dualidade/ } \\
\text { paradoxo }\end{array}$ & NAVEGADOR \\
\hline
\end{tabular}

Nota. Fonte: Tanure, B., Evans, P., \& Pucik, V. (2007). A gestão de pessoas no Brasil - virtudes e pecados capitais (p. 20). Rio de janeiro: Campus.

A partir dessa discussão teórica, foi realizado um estudo empírico, utilizando o modelo das quatro faces da GRH, apoiado na abordagem da divergência convergente, ou seja, na necessidade de adaptação dos modelos teóricos, principalmente no que tange à gestão de pessoas, à realidade e à cultura locais.

\section{METODOLOGIA}

Partindo-se do objetivo principal deste artigo - analisar a performance da GRH em empresas brasileiras, à luz do modelo das Quatro Faces da GRH, modelo este proposto por Tanure et al. (2007), e adaptado à realidade brasileira, optou-se por realizar um estudo descritivo, de caráter quantitativo e qualitativo, utilizando-se a triangulação. A triangulação, segundo Yin (2003), consiste na utilização de várias fontes de evidências, de maneira ordenada e lógica. Como Collis e Hussey (2003) afirmam, estratégias híbridas tornam as fontes de evidências mais relevantes. No caso desta pesquisa, foi utilizada a triangulação de dados (dados primários, referentes ao estudo de caso e secundários, provenientes da survey, coletados em momentos diferentes); a triangulação de investigadores (equipe formada por cinco pesquisadores); e a de metodologia (método quantitativo e qualitativo). Os dados quantitativos da survey possibilitaram identificar o estágio da atuação da GRH em empresas brasileiras, permitindo a generalização de dados. $\mathrm{O}$ estudo de caso na empresa brasileira possibilitou uma análise em profundidade da performance da GRH.

Os dados da survey são secundários, provenientes de pesquisa realizada no ano de 2005, com 172 presidentes de grandes empresas, selecionadas entre as 500 Maiores Empresas do país (Tanure, 2006). Esse levantamento mais amplo incluiu questões sobre as Quatro Faces, QF, da GRH, cujos resultados foram utilizados neste artigo, com o intuito de retratar a percepção dos dirigentes sobre a performance da GRH em empresas brasileiras.

Para a realização do estudo de caso, foi selecionada uma empresa do ramo financeiro - a Brasilprev - pelo critério de acessibilidade (Vergara, 1997). A empresa selecionada é uma das maiores companhias de previdência complementar aberta do país, com 1,6 milhão de clientes e carteira de mais de R \$ 9,65 bilhões em ativos administrados. Em 2005, a Brasilprev teve lucro líquido de R\$ 144,9 milhões, crescimento de $38,8 \%$ em relação ao ano anterior e arrecadação de $\mathrm{R} \$ 2,1$ bilhões (www.brasilprev.com.br). 
Para a coleta de dados do estudo de caso, foram utilizadas diversas técnicas, coerentemente com os objetivos a serem alcançados (Collis \& Hussey, 2003). Dados secundários da empresa foram coletados nos sites e em documentação formal como relatórios, comunicações internas, jornais, etc.

Os dados primários qualitativos coletados, que tiveram como base um roteiro construído a partir do modelo das quatro faces de RH, foram coletados por meio de entrevistas individuais e de grupos focais. Para a definição dos entrevistados, partiu-se do organograma da empresa, selecionando-se executivos, gerentes e técnicos que atuavam como clientes de RH ou na área de RH. Foram realizadas 14 entrevistas individuais: com o Presidente da empresa, com nove diretores e com quatro gerentes, a cargo de uma equipe de cinco pesquisadoras, que seguiram o roteiro proposto.

Os dados coletados por meio do grupo focal constituíram outra fonte de evidências. Essa técnica consiste na reunião de um grupo de pessoas (de 8 a 12), sob a coordenação de um moderador (um dos pesquisadores), para discutir o tema, apresentado por meio de roteiro tópico e flexível (Malhotra, 2006). Foram realizados três grupos focais, envolvendo 15 colaboradores: 4 especialistas de RH, 4 gerentes de área e 7 técnicos.

A coleta dos dados quantitativos do estudo de caso teve como foco a percepção de colaboradores da Brasilprev sobre a performance da GRH, segundo as Quatro Faces, QF, da GRH. O questionário foi elaborado a partir desse modelo. Para cada uma das faces, foram construídas sete afirmativas, avaliando-se a qualidade do serviço prestado por RH, por meio de uma escala Likert de cinco pontos. Em termos da avaliação, cada face poderia atingir um valor máximo de 35 pontos. No total geral, igual a 140 pontos, a faixa de pontuação de até 47 pontos indica baixa qualidade do RH; de 48 a 94, média qualidade; e de 95 a 140, alta qualidade.

O questionário foi elaborado a partir desse modelo. Para cada uma das faces, foram construídas sete afirmativas, avaliando-se a qualidade do serviço prestado por RH, por meio de uma escala Likert de cinco pontos. Em termos da avaliação, cada face poderia atingir um valor máximo de 35 pontos. No total geral, igual a 140 pontos, a faixa de pontuação de até 47 pontos indica baixa qualidade do RH; de 48 a 94, média qualidade; e de 95 a 140, alta qualidade.

Antes da aplicação do questionário, foi aplicado um pré-teste, em um grupo de profissionais, para verificar o entendimento semântico. Para verificar a aderência das afirmativas à literatura, discutiram-se as questões com um grupo de especialistas, o que gerou alterações na escala e em algumas afirmativas.

Foram aplicados 73 questionários em colaboradores da empresa, estratificados segundo a posição hierárquica, conforme Tabela 2; cinco questionários foram eliminados por apresentarem erros de preenchimento. O questionário foi respondido por grupos, na sala de treinamento da empresa, aplicado por duas entrevistadoras.

Tabela 2

Respondentes do Questionário, segundo a Posição Hierárquica na Empresa

\begin{tabular}{lcccc}
\hline Posição na empresa & Freqüência & $\%$ & $\begin{array}{l}\text { Total de } \\
\text { funcionários }\end{array}$ & $\begin{array}{l}\text { \% por posição } \\
\text { na empresa }\end{array}$ \\
\hline Presidência & 1 & 1,4 & 1 & 100 \\
Direção & 9 & 12,3 & 14 & 64,3 \\
Gerência & 12 & 16,4 & 27 & 44,4 \\
Técnico/outros & 51 & 69,9 & 340 & 15 \\
Total & 73 & 100,0 & 382 & 19,1 \\
\hline
\end{tabular}

Nota. Fonte: dados de pesquisa. 
Os dados do questionário foram analisados em duas etapas. Na primeira, realizou-se a análise exploratória dos dados - análise de dados ausentes e extremos. Depois, verificaram-se as propriedades psicométricas da escala: análise de unidimensionalidade, análise dos componentes principais e análise de confiabilidade.

A partir dos dados quantitativos e qualitativos, foi elaborado o caso da empresa, confrontando-se os resultados entre si e com a teoria pertinente. Apesar de o estudo de caso não permitir a generalização dos dados para outras empresas, ele permitiu a generalização teórica, essencial para a argumentação deste artigo (Yin, 2003). E os resultados da survey possibilitaram uma generalização para a realidade brasileira.

\section{APRESENTAÇÃO E DISCUSSÃO dOS RESULTADOS}

\section{A Percepção dos Presidentes sobre a Performance da GRH em Empresas Brasileiras}

Os resultados da percepção dos 172 presidentes de empresas brasileiras sobre a performance da área de RH em suas empresas indicaram que um terço dos presidentes classificou-a como operacional (que corresponde ao executor); para outro terço, existem boas políticas de RH implantadas (construtor); para apenas 9,2\% dos presidentes, a área de $\mathrm{RH}$ de suas empresas tem papel fundamental na modelagem do futuro do negócio (navegador), conforme apresentado na Tabela 3.

Tabela 3

Percepção dos Presidentes sobre a Performance da Área de RH

\begin{tabular}{|c|c|c|c|c|c|}
\hline \multirow[b]{2}{*}{ Realidade da Área de RH } & & \multicolumn{4}{|c|}{ Origem do capital } \\
\hline & & Nacional & Multinacional & Estatal & Total \\
\hline \multirow[t]{2}{*}{ Operacional } & Freqüência & 50 & 8 & 3 & 61 \\
\hline & \% Realidade da Área de RH & $41,0 \%$ & $17,0 \%$ & $100,0 \%$ & $35,5 \%$ \\
\hline \multirow{2}{*}{$\begin{array}{l}\text { Tem boas políticas de } \mathrm{RH} \\
\text { implantadas }\end{array}$} & Freqüência & 37 & 23 & & 60 \\
\hline & \% Realidade da Área de RH & $30,3 \%$ & $48,9 \%$ & & $34,9 \%$ \\
\hline \multirow{2}{*}{$\begin{array}{l}\text { Opera com qualidade os } \\
\text { processos de mudanças } \\
\text { estratégicas }\end{array}$} & Freqüência & 24 & 11 & & 35 \\
\hline & \% Realidade da Área de RH & $19,7 \%$ & $23,4 \%$ & & $20,3 \%$ \\
\hline \multirow{2}{*}{$\begin{array}{l}\text { Tem papel fundamental na } \\
\text { modelagem do futuro do } \\
\text { negócio }\end{array}$} & Freqüência & 11 & 5 & & 16 \\
\hline & \% Realidade da Área de RH & $9,0 \%$ & $10,6 \%$ & & $9,3 \%$ \\
\hline \multirow[t]{2}{*}{ Total } & Freqüência & 122 & 47 & 3 & 172 \\
\hline & \% Realidade da Área de RH & $100,0 \%$ & $100,0 \%$ & $100,0 \%$ & 100,0 \\
\hline
\end{tabular}

Nota. Qui-quadrado: P-valor $=0,05$

Fonte: dados de questionário.

A origem do capital das empresas apresentou associação significativa com a realidade do RH: maior percentual das empresas nacionais (41\%) do que as empresas multinacionais $(17 \%)$ percebe o $\mathrm{RH}$ de sua empresa como operacional (executor). Entre as empresas multinacionais, há maior destaque para "Tem boas políticas de RH implantadas" $(48,9 \%)$ - construtor - e "Opera com qualidade os processos de mudanças estratégicas" $(23,4 \%)$ - parceiro de mudança. As três empresas estatais consideram a área de RH operacional. 
Esses dados quantitativos foram usados para demonstrar como a GRH vem atuando no Brasil. Como se pode observar, o resultado geral da percepção dos presidentes das empresas indica o predomínio das faces de executor e construtor. Há de se ressaltar que, em empresas multinacionais, há a percepção da GRH atuando como parceiro de mudança; e somente $10 \%$ dos presidentes percebem a GRH auxiliando a navegar nos paradoxos organizacionais. Tal resultado demonstra que as quatro faces traduzem uma realidade na avaliação da performance da GRH no Brasil. Analisando os resultados do estudo de caso realizado na Brasilprev, pode-se aprofundar e compreender melhor o desempenho da GRH em empresas brasileiras.

\section{Estudo de Caso - A GRH na BrasilPrev}

A Brasilprev, empresa objeto deste estudo de caso, fundada em 1993, é uma das maiores empresas do setor de previdência privada do Brasil, resultado da associação entre o Banco do Brasil (uma empresa pública) e seguradoras do mercado. Em 1999, a Principal Financial Group, empresa americana de previdência aberta, tornou-se acionista da Brasilprev. A composição acionária atual da empresa é constituída pelo Banco do Brasil, com 49,99\% das ações, Principal Financial Group, 46,01\%, e Serviço de Apoio às Micro e Pequenas Empresas, Sebrae, 4,00\%.

A partir de 2003, a empresa passou por um processo de reestruturação. A mudança ocorreu com a indicação para a presidência de Eduardo Bom Ângelo, profissional com larga experiência de mercado. $\mathrm{O}$ foco de sua gestão baseia-se na valorização do fator humano como fundamento para o sucesso do resultado da empresa. Significativas alterações em variáveis como clima organizacional, motivação, participação e envolvimento de funcionários, cooperação e aumento da comunicação já podem ser observados. A participação na tomada de decisões e o grau de liberdade das pessoas aumentaram. Os meios de comunicação tornaram-se mais efetivos e a transparência beneficiou a troca de informações e conhecimentos. A Intranet hoje é um dos canais de comunicação mais importantes da empresa, juntamente com outros canais de comunicação, como o jornal mural Vitrine, o jornal impresso Enfoque e a Ouvidoria, que fortalecem o processo de mudança. A adoção da política Portas Abertas também proporcionou maior transparência na comunicação. Outra idéia originada na atual gestão é Escritório de Projetos, que gerencia os projetos que impactam o negócio da empresa, permitindo maior entrosamento entre os funcionários, disseminação de informações, participação na tomada de decisões e atuação por meio das equipes multidisciplinares.

Para os entrevistados, uma das principais vantagens competitivas é o comprometimento e a motivação de suas equipes. A pesquisa de opinião, realizada internamente, retrata um aumento no grau de satisfação dos funcionários: de 55\% em 2003, para $71 \%$ em 2004. O ano de 2004 foi um período marcado por premiações: a performance de Brasilprev rendeu-lhe oito importantes prêmios patrocinados pelas revistas de negócios brasileiras.

O modelo de gestão da empresa está baseado em quatro pilares de desenvolvimento: Qualidade de Vida, Empreendedorismo, Responsabilidade Social e Educação Financeira. Cada um desses pilares é conduzido por uma equipe multifuncional, que realiza e promove a autogestão, possibilitando o aprendizado e a disseminação do conhecimento gerado. As equipes funcionam de forma voluntária; levam-se em conta, portanto, a disponibilidade e a vontade de cada indivíduo em se incorporar à área que mais lhe agrade (Entrev. 11). Ainda assim, tem- se observado um conflito entre a participação nas equipes multifuncionais e o exercício cotidiano das tarefas funcionais, uma vez que o trabalho de rotina está ficando em segundo plano ou sobrecarregando os colaboradores.

Focando-se a performance da GperformanceRH na empresa pesquisada, no início de sua atuação, o RH podia ser considerado um departamento, com preocupação voltada para custos. A remuneração era o principal fator motivacional na época, conforme se pode constatar nas seguintes declarações: "As funções exercidas eram essencialmente processamento administrativo, folha de pagamento e treinamento básico. Essas funções eram exercidas de forma desvinculada do negócio" (Entrev. 2). Ou ainda: "O RH tinha função de entregar contracheques" (Grupo focal 1). 
Com as reformulações na empresa, ao longo dos últimos anos, quatro profissionais já passaram pela gerência de RH. Na atual gestão, a área de RH foi alçada à categoria de diretoria, sendo ocupada por André Camargo, Superintendente de Estratégia, que assumiu simultaneamente a área de Pessoas. Passados quatro meses, as equipes de RH foram modificadas: reduziu-se o número de três para duas, com a troca das lideranças, contratadas no mercado. "A idéia foi criar duas equipes que não disputem espaço e que troquem informações”, pontua André. Uma equipe é responsável pelo atendimento das diretorias de Tecnologia, Operações e de Investimento; e a outra, pelas diretorias de Marketing, Comercial, e Estratégia e Pessoas. Essa transformação da área de RH em Estratégia e Pessoas, ocorrida no final de 2004, ainda se mostra em fase de maturação: "Estratégia e Pessoas ainda não estão casadas", conforme afirmado no grupo focal 2.

As funções básicas de RH ainda vêm sendo desenvolvidas e aprimoradas, salientando-se as práticas de recrutamento e seleção internos, que geram maior satisfação, na medida em que os funcionários vislumbram possibilidade de crescimento e construção de carreira. "A organização começou a dar oportunidade de trabalho, começou a aproveitar mais os funcionários", comenta um colaborador (Entrev. 5). O processo necessita ainda de melhorias, mas já está sendo realizado de forma mais definida e estruturada, além de apresentar maior transparência. "O programa de recrutamento e seleção é bem definido - a forma com que acontece é bastante transparente" (Entrev. 4). Já as funções de treinamento e desenvolvimento ainda necessitam maior atenção. "O treinamento constitui uma das grandes falhas, há muito pouco. Hoje, a empresa oferece programa de bolsa educacional (pós graduação, graduação e idiomas). Isto é muito bom. O que não temos é programas para desenvolver as pessoas. Não tem nenhum hoje" (Entrev. 5).

O pacote de benefícios oferecido pela empresa é fator de satisfação para a grande maioria dos funcionários. O padrão de remuneração para o pessoal administrativo chega a ser $15 \%$ superior ao do mercado. O desenvolvimento de atividades que promovem a qualidade de vida dos funcionários está contribuindo para a visão positiva da atuação do RH na empresa: o Programa Qualidade de Vida no Trabalho compreende atividades de coral, teatro, palestras, ginástica laboral e sessões de cinema. Outras atividades existem na área de Empreendedorismo, Responsabilidade Social e Educação Financeira.

É dada grande importância a esses programas, apesar de incoerências entre o discurso e a prática. $\mathrm{O}$ programa de qualidade de vida, por exemplo, apesar de valorizado e efetivamente praticado pela base da empresa, é ‘boicotado silenciosamente' pelos níveis gerencial e diretivo. "Tem gestor que não deixa a pessoa sair da cadeira para fazer ginástica laboral. Ninguém levanta da cadeira quando o gestor está perto. Eles falam com medo: 'Não, agora não dá pra ir", ilustra um participante do grupo focal 1. "Eu nunca vi um gerente fazendo ginástica laboral", comenta um colaborador no grupo focal 1.

Os resultados indicam que já se percebe integração do RH com os objetivos estratégicos da empresa. Observa-se a tendência ao compartilhamento da responsabilidade pela gestão das pessoas entre os gerentes de linha e os especialistas da área. O RH mostra-se, hoje, preocupado em ouvir seus clientes, comunicar acontecimentos e ser reconhecido como parceiro no negócio da empresa (Entrev. 7). Está atuando mais próximo das áreas, no mesmo tempo em que tenta aumentar sua credibilidade junto a seus clientes. A Ouvidoria, criada em 2003, como sugestão de uma funcionária, tem permitido ao RH ouvir as demais áreas e está sendo muito bem aceita por todos, que a enxergam como um meio onde se tem "liberdade de reclamar" (Grupo focal 1). O RH vem incentivando outros meios que permitam o aumento da valorização e a participação das pessoas nas decisões da empresa. A introdução de ferramentas como o Balanced Scorecard, avaliação de desempenho e a criação das equipes multifuncionais demonstram iniciativas positivas do RH.

Os colaboradores têm grande expectativa em relação à atuação futura do RH. Eles enxergam as mudanças e o desenvolvimento da área. O RH conta com o apoio da empresa. "O RH está no caminho certo, tem rumo e direção. Tem consciência das deficiências e vem fazendo um esforço visível para definir um plano" (Entrev. 3). Essas ações, apesar de ainda serem incipientes e carentes de melhoria, revelando gaps na atuação do RH, são percebidas positivamente pela maioria dos funcionários. 


\section{A Percepção dos Colaboradores sobre as Quatro Faces da GRH - Resultado dos Questionários}

Para análise exploratória do questionário, seguiram-se as recomendações de Churchill (1979) e Spector (1992). Verificaram-se primeiramente os valores extremos (outliers) e respostas omissas, que não foram encontrados. Procedeu-se então à extração dos fatores, por meio da análise dos componentes principais. Os procedimentos revelaram uma matriz composta por sete fatores principais. A matriz de correlação mostrou-se favorável, com $\mathrm{KMO}=0,742$, o que classifica a adequação da amostra como regular, segundo os critérios de Hair, Anderson, Tathan e Black. (1998). A indicação de sete fatores obedeceu ao critério de distribuição dos valores próprios (eigenvalue) superior a 1. Foi também aplicado, nesta análise, o critério relativo à porcentagem mínima de 5,5\% de explicação para os fatores extraídos. Dessa forma, destacaram-se quatro componentes que representam $55,59 \%$ da variância total explicada.

Os resultados dessa primeira análise permitem supor a existência de certa convergência entre os dados empíricos e a teoria, com relação à existência das quatro faces, revelada com a extração forçada dos quatro componentes. Entretanto a análise inicial dos componentes principais indica certa dispersão de algumas variáveis que representam as faces - elas não se comportam como o esperado no crivo de correção, com o enquadramento das questões do instrumento à teoria, indicando necessidade de refinamento da escala. Esse resultado poderia ser atribuído a problemas na amostra - baixo número de respondentes, não satisfazendo as exigências para a realização desta técnica. Segundo Hair et al. (1998), seriam necessários 10 respondentes por questão, o que perfaria uma amostra de 280 respondentes, uma vez que o questionário é composto por 28 questões. Esse resultado pode ainda sinalizar a necessidade de refinamento na escala ou de uma revisão na construção teórica, reforçando a necessidade de realização de estudos posteriores mais aprofundados.

Foi então calculado o coeficiente alfa de Cronbach, para verificar a consistência interna da escala, ou seja, que resultados consistentes ela produz, ao se fazerem medições repetidas de determinada característica. Segundo Hair et al. (1998), o limite inferior aceito é 0,70, podendo-se aceitar 0,60 em pesquisa exploratória. Já Malhotra (2006) aponta que o coeficiente igual ou menor que 0,6 indica confiabilidade insatisfatória. Todos os coeficientes Alfa de Cronbach foram superiores a 0,6, revelando confiabilidade satisfatória. A Tabela 4 apresenta o resultado do teste para a escala proposta.

Tabela 4

Teste de Confiabilidade da Escala As Quatro Faces da GRH

\begin{tabular}{lllllllll}
\hline Papel & \multicolumn{9}{c}{ Questões } & & Alfa de Cronbach \\
\hline Executor & $1 \mathrm{~b}$ & $2 \mathrm{c}$ & $3 \mathrm{a}$ & $4 \mathrm{~d}$ & $5 \mathrm{~d}$ & $6 \mathrm{~b}$ & $7 \mathrm{a}$ & 0,6859 \\
Construtor & $1 \mathrm{c}$ & $2 \mathrm{~b}$ & $3 \mathrm{~d}$ & $4 \mathrm{a}$ & $5 \mathrm{a}$ & $6 \mathrm{c}$ & $7 \mathrm{~b}$ & 0,6376 \\
Parceiro & $1 \mathrm{~d}$ & $2 \mathrm{a}$ & $3 \mathrm{c}$ & $4 \mathrm{~b}$ & $5 \mathrm{c}$ & $6 \mathrm{a}$ & $7 \mathrm{c}$ & 0,8433 \\
Navegador & $1 \mathrm{a}$ & $2 \mathrm{~d}$ & $3 \mathrm{~b}$ & $4 \mathrm{c}$ & $5 \mathrm{~b}$ & $6 \mathrm{~d}$ & $7 \mathrm{~d}$ & 0,8086 \\
\hline
\end{tabular}

Nota. Fonte: dados de pesquisa.

Contudo, para os papéis Executor e Construtor, o valor do coeficiente Alfa foi próximo a 0,6. Foram realizadas então correlações entre os itens e o escore total, a fim de verificar se alguma questão precisaria ser omitida, conforme apresentado na Figura 1. 

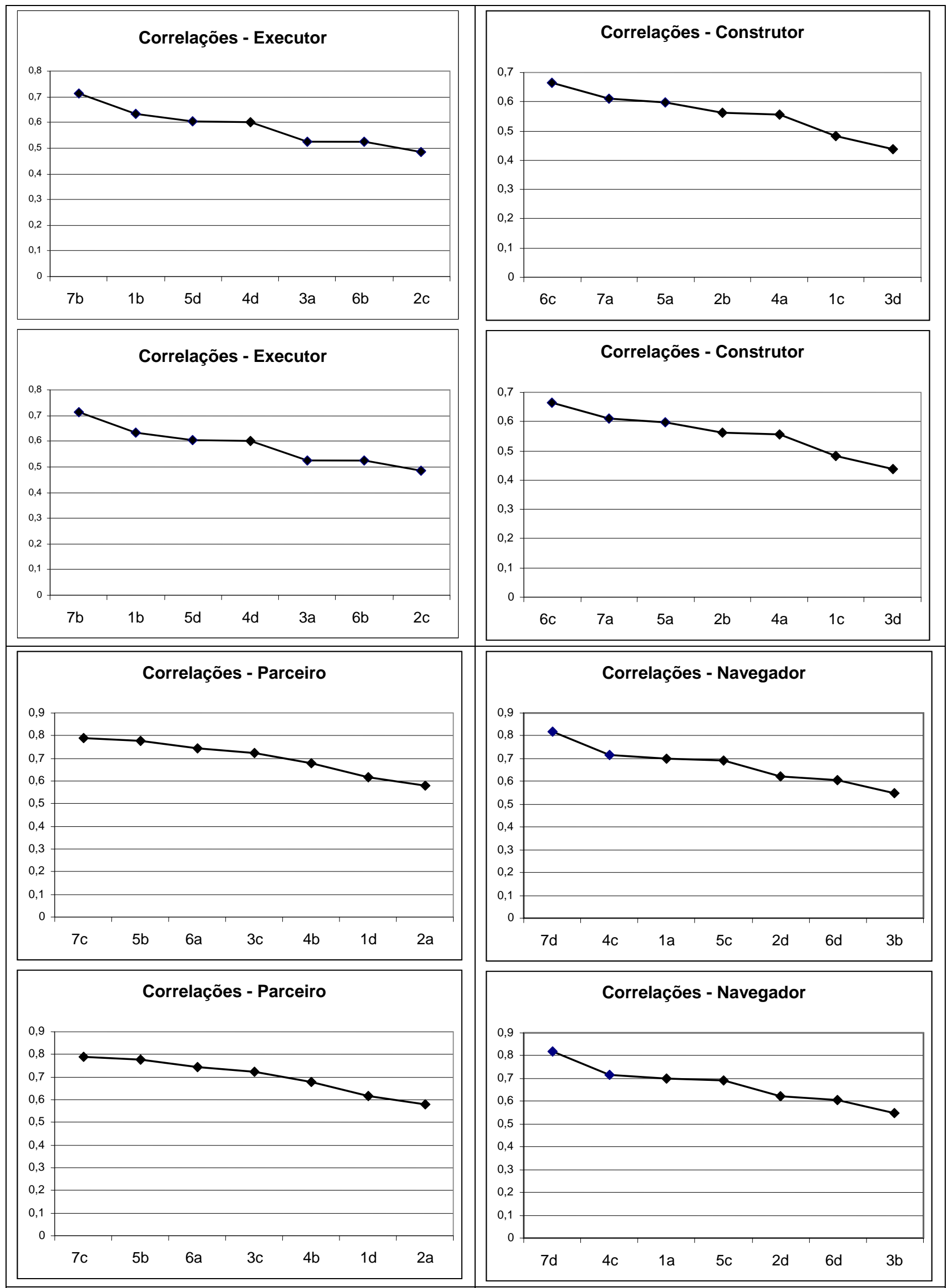

Figura 1. Correlação entre as Questões e as Quatro Faces da GRH Fonte: dados de pesquisa 
Não houve nenhuma correlação próxima de zero, tampouco pontos de quebra nos gráficos, o que indica que nenhuma questão precisa ser omitida da análise.

Os resultados dos questionários aplicados aos colaboradores indicam que a avaliação geral do RH foi igual a 87,5 pontos, podendo ser classificado como qualidade média. As respostas foram bastante semelhantes, como pode ser visualizado no histograma (Figura 2), com distribuição próxima da curva normal (formato de sino), cujo desvio padrão foi relativamente pequeno. Essa situação torna a média uma boa medida para resumir a opinião dos entrevistados. As médias das questões referentes ao RH foram estratificadas segundo sexo, idade e posição na empresa; mas não foram encontradas diferenças estatisticamente significativas em nenhuma questão, confirmando a convergência de opiniões dos funcionários da empresa.

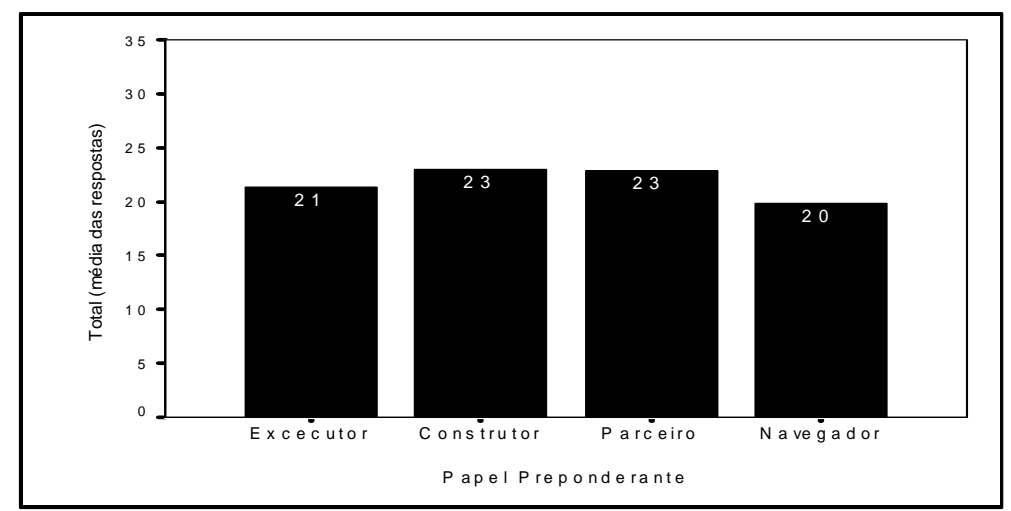

Figura 2. A Performance do RH na Empresa Pesquisada Segundo as Quatro Faces

Fonte: dados de questionário

O resultado da classificação da GRH, segundo as quatro faces, foi confrontado com as informações coletadas nas entrevistas e grupos focais; confirmou-se a percepção confrontadas com os resultados dos questionários aplicados aos colaboradores; assim como a percepção da predominância das faces do Construtor e do Parceiro de Mudança (Figura 2). Observa-se uma coerência nesse resultado, uma vez que, recentemente, houve a junção da área de Pessoas e de Estratégia com a delegação formal de poder pela presidência, para a efetivação das mudanças necessárias. Entretanto essas mudanças são muito recentes para já se terem consolidado, pois estão em vigor somente há quatro meses. Aparentemente, a GRH apresenta a relevância dessas faces, o que não se sustenta em uma análise mais aprofundada de sua atuação.

A avaliação geral do RH foi igual a 87,5 pontos, podendo ser classificado como de qualidade média. As respostas foram bastante semelhantes, como pode ser visualizado no histograma, com distribuição próxima da curva normal (formato de sino), cujo desvio padrão foi relativamente pequeno. Essa situação torna a média uma boa medida para resumir a opinião dos entrevistados. As médias das questões referentes ao RH foram estratificadas segundo sexo, idade e posição na empresa, mas não foram encontradas diferenças estatisticamente significativas em nenhuma questão, confirmando a convergência de opiniões dos funcionários da empresa.

\section{Discussão dos Resultados do Estudo de Caso}

Apesar de os resultados da pesquisa quantitativa indicarem o desempenho do RH como construtor e parceiro de mudança, a análise dos dados da pesquisa qualitativa revela que os processos da função RH em si ainda não estão adequadamente estruturados, interligados entre si ou com os demais processos. Modernas ferramentas, tais como Balanced Scorecard, escritório de projetos, sistema de avaliação de desempenho e equipes multifuncionais, que foram recentemente implantados, ainda carecem de integração entre si. As funções básicas de RH ainda não estão implementadas de forma adequada; destaca-se a função de Treinamento e Desenvolvimento que, segundo a percepção de alguns colaboradores, deve indicar que deva ser aprimorada. 
Esse resultado da pesquisa quantitativa - avaliação como construtor e parceiro de mudança - talvez possa ser atribuído ao alto grau de expectativa dos colaboradores em face do RH. Os colaboradores, em função das modernas práticas de gestão de pessoas, avaliam o RH em nível mais elevado do que as práticas de $\mathrm{RH}$ efetivamente demonstram ser. A análise das políticas e práticas de $\mathrm{RH}$ indica a carência do exercício das funções básicas de RH, características do papel do executor. Mas, como a área vem sendo gerenciada pelo executivo de Estratégia, há interligação, tanto no aspecto formal - da hierarquia - quanto no simbólico - da posição de poder atribuída pelo presidente à área. Tais aspectos podem ter contribuído para a classificação da área na face do parceiro de mudança.

A sustentação dessa parceria se dá pelo modelo de gestão baseado nos quatro pilares, no escritório de projetos e nas equipes multifuncionais. A utilização dessas ferramentas, principalmente em função das características, tanto positivas como negativas, da flexibilidade e criatividade característica da cultura brasileira, bem como em função da plasticidade das técnicas modernas de gestão podem gerar impactos negativos. Apesar da percepção positiva dos funcionários quanto aos grupos multifuncionais, observa-se um conflito com as atividades funcionais. A flexibilidade dos colaboradores facilita o envolvimento nas equipes multifuncionais; mas o trabalho de rotina passa a segundo plano ou sobrecarrega os colaboradores. Aliando-se a isto, as atividades de ginástica, palestras, o excesso de reuniões e outros eventos, realizados no horário de do trabalho, contribui-se para diminuir o tempo gasto com a execução; portanto as políticas e práticas da GRH ainda carecem de alinhamento e precisam ser alinhadas aos objetivos da empresa.

Essa classificação, em parte, encontra respaldo em pesquisas realizadas no Brasil, nas quais se postula a atuação do RH em nível estratégico, conforme apontado em Caldas e Wood (1999), Fischer e Albuquerque (2001), Hanashiro et al. (2001), Sarsur (1997), Tanure et al. (2007).

Tal resultado parece ser coerente com a argumentação da existência de dois segmentos na face do executor: o focado em atividade burocráticas e o aderente à modernidade, conforme apontado em pesquisas realizadas no Brasil por autores como Bosquetti e Albuquerque (2005), Fischer e Albuquerque (2001), Lacombe (2006), Sarsur (1997), Tanure et al. (2007) e Wood (1995). Observa-se que o discurso sobre a importância dos recursos humanos, com a aplicação das modernas ferramentas de gestão, não encontra respaldo no dia-a-dia da gestão. Conforme detectado por Caldas e Wood (1999), a modernidade das ferramentas de gestão, incluindo-se o grande número de premiações por bom desempenho, tende a encobrir a inconsistência interna e a falta de articulação entre a GRH e a estratégia do negócio. Confirma-se a tendência à adoção de modismo e à importação de modelos de gestão estrangeiros em empresas brasileiras.

Observa-se ainda que os dados qualitativos não revelam a percepção da performance do RH no papel do navegador, lidando com as dualidades e paradoxos organizacionais. Essa percepção pode estar ligada à recente estruturação da área, confirmando o que pode confirmar a proposição de Tanure et al. (2007) sobre a evolução das faces.

\section{CONSIDERAÇÕES FINAIS}

O objetivo deste artigo - analisar a performance da GRH em empresas brasileiras - foi atingido por meio da discussão teórica e da pesquisa empírica apresentada. Para analisar a performance da GRH, optou-se por utilizar o modelo As Quatro Faces da Gestão de Recursos Humanos, adotando-se a abordagem da divergência convergente, que considera que práticas como a de gestão de pessoas devam adequar-se às especificidades regionais e de cada empresa, enquanto algumas outras práticas ligadas às dimensões da organização, como a estratégia, podem ser universais. Esse modelo considera que a relação entre a GRH e a performance organizacional pode ser analisada por meio de quatro diferentes faces: executor, construtor, parceiro de mudança e o navegador. $\mathrm{O}$ executor desenvolve e implementa as funções operacionais da GRH, mesmo que elas não estejam conectadas entre si ou com a estratégia da organização. O construtor edifica os fundamentos da GRH, desenvolvendo as funções 
de forma consistente (entre si e com a estratégia; essa é a diferença entre o executor e o construtor). $\mathrm{O}$ parceiro de mudança busca o realinhamento da estratégia da organização com o ambiente externo. $\mathrm{O}$ navegador auxilia a organização a enfrentar as contradições e paradoxos inerentes às empresas globais.

Para analisar o desempenho da GRH no Brasil, utilizaram-se dados secundários de uma survey realizada com 172 presidentes das 500 maiores empresas no Brasil, objetivando identificar a percepção sobre a classificação da GRH nas quatro faces. Para melhor entender como a GRH atua, analisaram-se os resultados de um estudo de caso realizado em uma empresa do ramo financeiro, cujos dados foram coletados por meio de entrevistas, grupos focais e questionário. A triangulação permitiu um aprofundamento no entendimento sobre a performance da GRH na análise dos dados.

Os resultados da survey indicaram que os presidentes de empresas de capital nacional consideram que a GRH pode ser classificada predominantemente como executora, seguida da face de construtora. Em empresas multinacionais, ocorre o predomínio da face do construtor, apesar de a face parceiro de mudança já se apresentar com certa expressividade. Portanto pode-se concluir que a GRH no Brasil não pode ser considerada estratégica, da forma como muitas pesquisas tentam demonstrar. Em empresas menos influenciadas pela gestão estrangeira, a face do executor ainda prevalece. Isso parece indicar que a GRH no Brasil ainda precisa construir seu próprio caminho, a sua forma de gerenciar pessoas, buscando um jeito brasileiro de operar GRH.

Tomando como base as quatro faces de $\mathrm{RH}$, pode-se concluir que os funcionários da empresa pesquisada têm a percepção de que o RH está caminhando para um estado de parceria. Há, de fato, uma atitude que demonstra esse esforço da área, mais nitidamente após a criação da área Pessoas e Estratégia, com a conjunção das funções de planejamento e de gestão de RH. Entretanto essa junção é recente. Para que o RH seja efetivamente parceiro estratégico, é preciso que exerça também o papel de executor e de construtor dos fundamentos: isto significa executar atividades funcionais da área e construir a sua base de sustentação. Essa base inclui revisão, definição clara e melhoria dos processos inerentes à área, além de exercer os papeis estratégicos. Os resultados indicam fragilidade em algumas funções de RH, notadamente a de Treinamento e Desenvolvimento.

Por outro lado, os resultados das entrevistas indicam que, atualmente, o RH tem exercido atividades de ponta, consideradas modernas e adequadas às grandes corporações, como ginástica laboral, equipes multifuncionais e palestras. Ainda assim, essas atividades estão atingindo prioritariamente o nível operacional, tendo como participantes pessoas do nível administrativo. Não se percebe ressonância entre o discurso sobre a importância dos recursos humanos, articulado pelos executivos da empresa, e as práticas observadas.

Há na organização uma espécie de encantamento com a atual gestão. Os oito prêmios conquistados pela empresa no ano de 2004 podem ser parcialmente explicados pelo grau de comprometimento e de entusiasmo dos colaboradores. Esses aspectos caracterizam a face do executor, típica do segundo segmento. Ocorre a utilização de ferramentas de gestão de última geração, normalmente importadas dos grandes centros, embora a modernidade dessas ferramentas tenda a encobrir a inconsistência interna da GRH e a desarticulação com a estratégia do negócio.

Em relação à face do construtor, pode-se concluir que há uma expectativa positiva de que os profissionais contratados consigam implementar as ferramentas adequadas, atreladas à estratégia da empresa e consistentes entre si. Apesar de ter sido relativamente bem avaliado na face construtor, não se percebe ainda a construção sólida dos fundamentos de RH, em termos de implantação de práticas e técnicas adequadas à cultura da empresa. Os processos, ainda muito recentes, carecem de estruturação.

A face mais bem avaliada foi a de parceiro da mudança, o que parece refletir o momento atual da empresa, com a criação da área de Estratégia e Pessoas. Investe-se atualmente no realinhamento tanto interno quanto externo e na formação de parceria entre os gestores da linha e os profissionais da área de $\mathrm{RH}$, o que caracteriza a relação parceiro de mudanças. Uma das premissas básicas dessa parceria é a de que os profissionais de RH têm de ser dignos de confiança, conhecedores das mudanças externas que conduzirão o realinhamento e envolvidos na estratégia do negócio. $\mathrm{Na}$ medida em que o RH se 
estrutura em duas equipes, atuando como consultoria interna para o atendimento das áreas de produção e de apoio da empresa, há possibilidade de viabilização dessa parceria. Entretanto, por essa reestruturação ser ainda recente, encontra-se em fase de maturação.

Em relação à face do navegador, avaliada em menor nível de qualidade, há indicativos de carência do RH em atuar na administração construtiva da tensão entre forças opostas, características do mundo globalizado.

Apesar de essas faces do RH não se constituírem como etapas, há gradual evolução nos papéis exercidos pela área. O RH da empresa pesquisada ainda necessita investir na construção de fundamentos sólidos, que deem consistência e coerência à sua atuação como parceiro de mudança e como navegador. As práticas de RH adotadas pela empresa, apesar de serem de última geração e modernas, não estão articuladas entre si e não apresentam consistência interna e externa, caracterizando, dessa forma, a face do executor. Elas estão até em consonância com os quatro pilares de sustentação, definidos como objetivos da organização; mas falta a articulação entre elas. Assim, em sua face mais aparente, a GRH da Brasilprev revela a modernidade de suas práticas, premiadas nacionalmente, embora seja ainda característica da face do executor.

Pode-se concluir que os resultados empíricos, tanto da survey como do estudo de caso, dão sustentação à argumentação proposta neste artigo: a necessidade de adaptar as práticas de RH à realidade local. Assim, a abordagem da divergência convergente é confirmada - uma ligação entre a abordagem universalista (melhor maneira para se gerenciar) e a relativista (adaptação à cultura local). A abordagem da divergência convergente é defendida principalmente em questões relacionadas à gestão de recursos humanos. Não se pretende afirmar que este modelo das Quatro Faces da GRH seja específico da realidade brasileira, ou de países em desenvolvimento. Mas, dadas as características culturais e o desenvolvimento histórico das empresas no Brasil, a face do executor emerge, incorporada ao modelo inicialmente proposto para países desenvolvidos. Sugerem-se pesquisas em empresas de países desenvolvidos e em desenvolvimento que possibilitem testar a adequação do modelo. Sugere-se também o desenvolvimento de novas pesquisas para o desenvolvimento de testes psicométricos para validação da escala proposta para mensurar as Quatro Faces da GRH.

Artigo recebido em 15.08.2008. Aprovado em 31.07.2009.

\section{REFERÊNCIAS BIBLIOGRÁFICAS}

Arthur J. B., \& Boyles T. (2007). Validating the human resource system structure: a levels-based strategic HRM approach. Human Resource Management Review, 17(1), 77-92.

Becker, B. E., \& Gerhart, B. (1996). The impact of human resource management on organizational performance: progress and prospects. Academy of Management Journal, 39(4), 779-801.

Becker, B. E., \& Huselid, M. A. (2006). Strategic human resources management: Where do we go from here? Journal of Management, 32(6), 898-925.

Bosquetti, M. A., \& Albuquerque, L. G. (2005, setembro). Gestão estratégica de pessoas: visão do RH $\mathrm{x}$ visão dos clientes. Anais do Encontro Nacional da Associação Nacional de Pós-Graduação e Pesquisa em Administração, Brasília, DF, Brasil, 29.

Burke, R. J., \& Cooper, C. L. (Ed). (2005). Reinventing HRM - Challenges and new directions. London/New York: Routledge.

Caldas, M. P., \& Wood, T., Jr. (1999). Transformação e realidade organizacional: uma perspectiva brasileira. São Paulo: Atlas. 
Cançado, V. L., Coutinho, P. T., Sant'Anna, A. S. de, \& Almeida, M. G. R. das (2005, setembro). Novos papéis de recursos humanos: velhas fórmulas em novas embalagens? Anais do Encontro Nacional da Associação Nacional de Pós-Graduação e Pesquisa em Administração, Brasília, DF, Brasil, 29.

Cappelli, P., \& Newmark, D. (2001). Do "high performance" work practices improve establishment level outcomes? Industrial and Labor Relations Review, 54(4), 737-775.

Castro, J. H. M. de, Kilimnik, Z. M., \& Sant'Anna, A. S. de (2008). Modernidade organizacional em gestão de pessoas como base para a incorporação de modelo de gestão por competências. RACEletrônica, 2(1), 105-122. Recuperado em 20 junho, 2008, de http://www.anpad.org.br/periodicos/arq_pdf/a_688.pdf

Chiavenato, I. (1997). Gerenciando pessoas. O passo decisivo para a administração participativa. São Paulo: Makron books.

Child, J. (2002). Theorizing about organization cross-nationally: an introduction. In M. Warner \& P. Joynt (Eds.), Managing across cultures: issues and perspective (pp. 26-56). London: Thomson Learning.

Churchill, G. A., Jr. (1979). A paradigm for developing better measures of marketing constructs. Journal of Marketing Research, 16(1), 64-73.

Collis, J., \& Hussey, R. (2003). Business research: a practical guide for undergraduate and postgraduate students (2nd ed.). UK: Palgrave Macmillan.

Dessler, G. (2002). A framework for human resource management (2nd ed.). New Jersey: Prentice Hall.

Dutra, J. S. (2002). Gestão de pessoas - modelo, processos, tendências e perspectivas. São Paulo: Atlas.

Elvira, M. M., \& Dávilla, A. (Ed.) (2005). Managing human resources in Latin America: an agenda for international leaders. London, NY: Routledge.

Evans, P. A. L., \& Farquhar, A. (1989). Case series - Marks \& Spencer (A) and (B). Fontainebleau: INSEAD.

Evans, P. A. L., Pucik, V., \& Barsoux, J.-L., (2002). The global challenge: frameworks for international human resource management. New York: McGraw-Hill.

Fischer, A. L., \& Albuquerque, L. (2001, setembro). Tendências que orientam as decisões dos formadores de opinião em gestão de pessoas no Brasil - RH 2010. Anais do Encontro Nacional da Associação Nacional de Pós-Graduação e Pesquisa em Administração, Campinas, SP, Brasil, 25.

Glanz, E. F., \& Bailey L. K. (1993). Benchmarking. Human Resource Management, 31(1/2), 9-20.

Godard, J., \& Delaney J. T. (2000). Reflections on the 'high performance' paradigm's implications for industrial relations as a field. Industrial and labor Relations Review, 53(3), 482-502.

Hair, J. F., Anderson, R. E., Tathan, R. L., \& Black, W. O. (1998). Multivariate data analyses (5th ed.). New Jersey: Prentice Hall.

Hanashiro, D. M. M., Teixeira, M. L. M., \& Zebinato, A. N. (2001, setembro). Os papéis desempenhados pelos profissionais de recursos humanos contribuem para a vantagem competitiva sustentável? Anais do Encontro Nacional da Associação Nacional de PósGraduação e Pesquisa em Administração, Campinas, SP, Brasil, 25. 
Huselid, M. (1995). The impact of human resource management practices on turnover, productivity, and corporate financial performance. Academy of Management Journal, 40(1), 171-88.

Jackson, S. E., \& Schuler, R. (1999). Managing human resources. Cincinnati: South-Western.

Lacombe. B. M. B. (2006, setembro). Políticas e práticas de gestão de pessoas: as abordagens estratégica e institucional. Anais do Encontro Nacional da Associação Nacional de PósGraduação e Pesquisa em Administração, Salvador, BA, Brasil, 30.

Lawler, E. E. (1992). The ultimate advantage: creating the high involvement organization. San Francisco: Jossey-Bass.

Lengnick-Hall, C. A., \& Lengnick-Hall, M. L. (1988). Strategic human resources management: A review of the literature and a proposed typology. Academy of Management Review, 13(3), 454-70.

Lepak, D. P., Takeuchi, R., Erhardt, N. L., \& Colakoglu, S. (2006). Emerging perspectives on the relationship between HRM and performance. In R. J. Burke \& C. L. Cooper (Eds.). The human resources revolution: why putting people first matters (pp. 31-54). Oxford: Elsevier.

Malhotra, N. K. (2006). Marketing research: an applied orientation (5th ed.). India: Prentice Hall.

Meshoulam, I., \& Baird, L. (1987). Proactive human resource management. Human Resource Management, 26(4), 483-503.

Milkovich, G. T., \& Boudreau, J. W. (1997). Human resource management (8th ed.). Chicago: Irwin/McGraw Hill.

Neal, J. A. \& Tormley, C. L. (1995). From incremental change to retrofit: Creating high performance work systems. Academy of Management Executive, 9(1), 42-54.

Noe, R., Hollenbeck, J., Wright, P. M. \& Gerhart, B. (1999). Human resource management. New York: McGraw-Hill/Irwin.

Pfeffer, J. (1998). The human equation: building profits by putting people first. Boston: Harvard Business School Press.

Sarsur, A. M. (1997, setembro). Empregabilidadex empresabilidade. Anais do Encontro Nacional da Associação Nacional de Pós-Graduação e Pesquisa em Administração, Rio das Pedras, RJ, Brasil, 21.

Spector, P. E. (1992). Summated rating scale construction: an introduction. Age Series: Quantitative Applications in the Social Sciences (Vol. 82). Los Angeles: Sage.

Tanure, B. (2005). Gestão à brasileira: uma comparação entre América Latina, Estados Unidos, Europa e Ásia (2a ed.). São Paulo: Atlas.

Tanure, B. (2006). Pesquisa com dirigentes de empresas brasileiras (Relatório de Pesquisa), Belo Horizonte, MG, Fundação Dom Cabral.

Tanure, B., Evans, P., \& Pucik, V. (2007). A gestão de pessoas no Brasil - virtudes e pecados capitais. Rio de janeiro: Campus.

Torrington, D., \& Hall, L. (1995). Human resource management. London: Prentice Hall.

Ulrich, D. (1997). Human resource champions: the next agenda for adding value and delivering results. Boston, MA: Harvard Business School Press. 
Vasconcelos, I. F. G. de, Mascarenhas, A. O., \& Vasconcelos, F. C. de (2006). Gestão do paradoxo "passado versus futuro": uma visão transformacional da gestão de pessoas. RAE-eletrônica, 5(1), Recuperado em 27 maio, 2009, de http://www.fgvsp.br/institucional/biblioteca/pe/raeeletronica/SP000402862.pdf

Vergara, S. C. (1997). Projetos e relatórios de pesquisa em administração. São Paulo: Atlas.

Weiss, D. S. (1999). High-performance HR: leveraging human resources for competitive advantage. New York: John Wiley.

Whitfield, K., \& Poole, M. (1997). Organizing employment for high performance: theories, evidence and policy. Organization Studies, 18(5), 745-64.

Wood, T., Jr. (1995). Mudança organizacional: aprofundando temas atuais em administração de empresas. São Paulo: Atlas.

Wright, P. M., \& McMahon, G. C. (1992). Alternative theoretical perspectives on strategic human resource management. Journal of Management, 18(2), 295-320.

Yin, R. K. (2003). Case study research: design and methods (3rd ed.). California: Sage. 